\title{
Creation of Digital Contours That Approach the Characteristics of Cartographic Contours
}

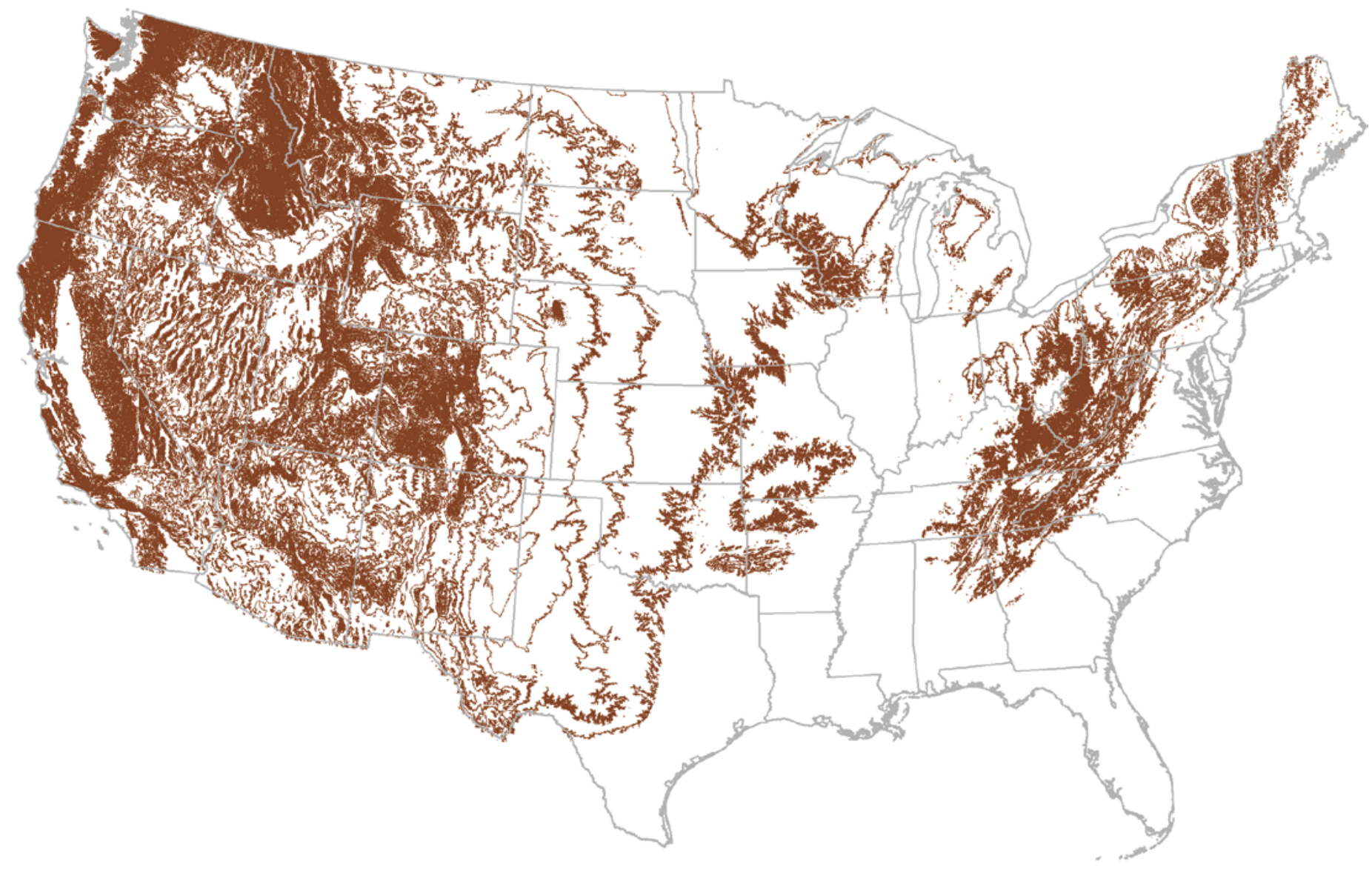

Scientific Investigations Report 2012-5167 
Cover. One thousand foot contours extracted from the national contour dataset described in this report. 


\section{Creation of Digital Contours That Approach the Characteristics of Cartographic Contours}

By Dean J. Tyler and Susan K. Greenlee

Scientific Investigations Report 2012-5167 


\title{
U.S. Department of the Interior \\ KEN SALAZAR, Secretary \\ U.S. Geological Survey \\ Marcia K. McNutt, Director
}

\author{
U.S. Geological Survey, Reston, Virginia: 2012
}

For more information on the USGS - the Federal source for science about the Earth, its natural and living resources, natural hazards, and the environment, visit http://www.usgs.gov or call 1-888-ASK-USGS.

For an overview of USGS information products, including maps, imagery, and publications, visit http://www.usgs.gov/pubprod

To order other USGS information products, visit http://store.usgs.gov

Any use of trade, firm, or product names is for descriptive purposes only and does not imply endorsement by the U.S. Government.

Although this information product, for the most part, is in the public domain, it also may contain copyrighted materials as noted in the text. Permission to reproduce copyrighted items must be secured from the copyright owner.

Suggested citation:

Tyler, D.J., and Greenlee, S.K., 2012, Creation of digital contours that approach the characteristics of cartographic contours: U.S. Geological Survey Scientific Investigations Report 2012-5167, 31 p. with appendixes. 


\section{Contents}

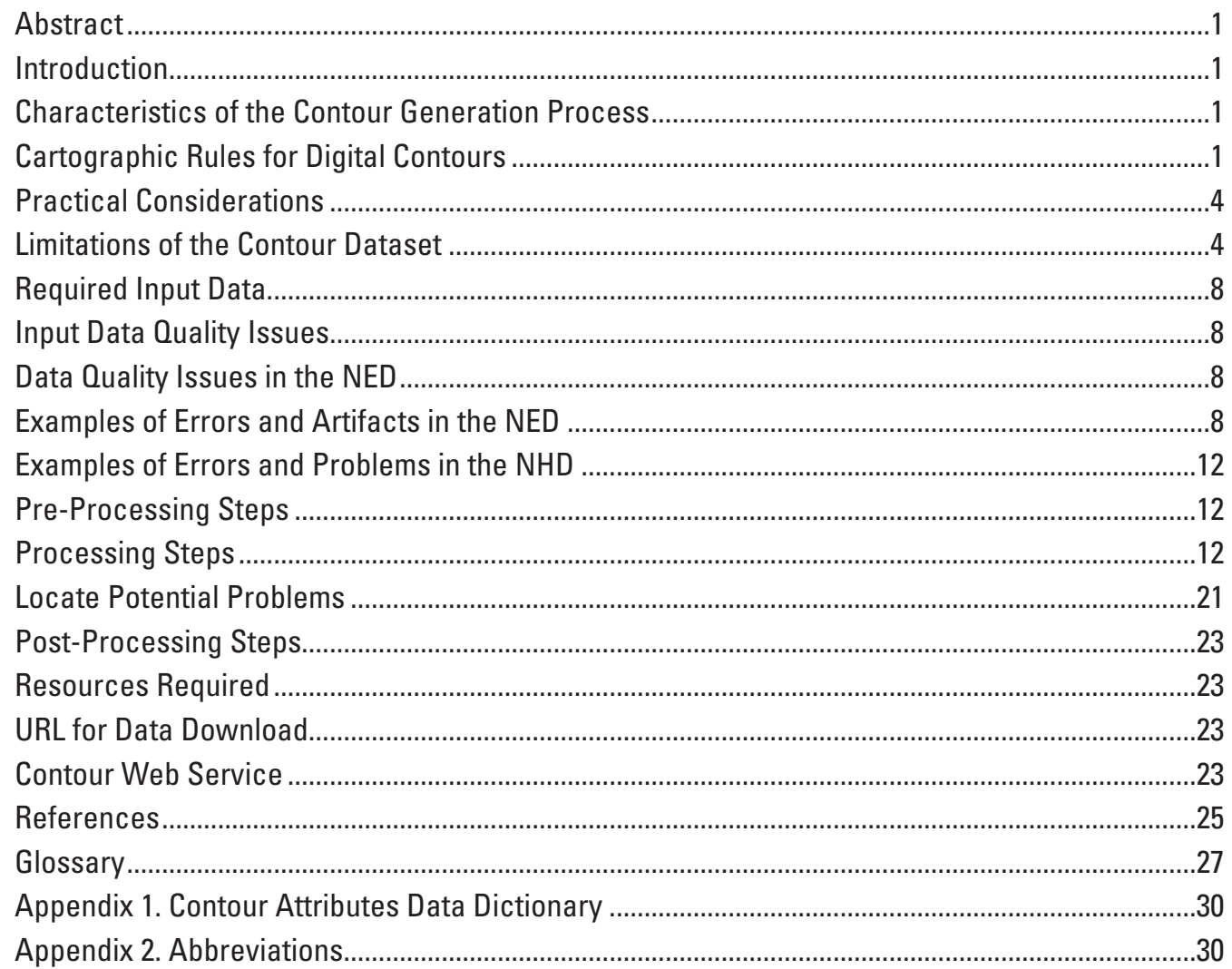




\section{Figures}

1. Map showing small contours that are retained by interpolating at a cell size of $1 / 27$ arc-second

2. Map showing how hydro-enforcement has improved the contours so they cross the river correctly at an approximate right angle .....

3. Map showing reentrant contours with improved crenulations, which are indicated by red circles

4. Map showing the effects on contours generated from elevation data referenced to the National Geodetic Vertical Datum of 1929 and the North American Vertical Datum of 1988

5. Map showing Contour Interval Plan based on statistical analysis of February 2009 National Elevation Dataset.

6. Map showing results of routing contours around waterbodies by changing the surface elevation of each waterbody

7. Maps showing $A$, Triangulated Irregular Network artifacts in the river distort the water surface in the National Elevation Dataset, resulting in spurious contours in the river. $B$, Improved contours in relation to the river channel after removal of TIN artifacts

8. Map showing an example of flattening a Digital Elevation Model to alleviate "wormwood"

9. Maps showing $A$, A poorly defined river channel in National Elevation Dataset, with associated inaccurate contours. $B$, The river channel and improved contours after Inverse Distance Weighted-interpolation treatment

10. Maps showing $A, A$ National Hydrography Dataset flowline that was digitized incorrectly so it flows uphill. $B$, Good reentrant contours obtained by reversing the order of vertices in the flowline

11. Map showing incorrect contour representation, caused by a National Hydrography Dataset flowline traversing a hill

12. Map showing the advantage of interpolating the new elevation surface at a cell size of $1 / 27$ arc-second.

13. Map showing contours as generated from four variations of TopoToRaster.

14. Map showing final product after a new elevation surface is generated for the river....19

15. Map showing zoomed-in view of a new river surface

16. Map showing contours generated from an unmodified National Elevation Dataset raster as well as fully processed contours.

17. Map showing large depressions, which are defined in post-processing by comparing attribute values on contours in adjacent quads. 


\title{
Creation of Digital Contours That Approach the Characteristics of Cartographic Contours
}

\author{
By Dean J. Tyler and Susan K. Greenlee
}

\begin{abstract}
The capability to easily create digital contours using commercial off-the-shelf (COTS) software has existed for decades. Out-of-the-box raw contours are suitable for many scientific applications without pre- or post-processing; however, cartographic applications typically require additional improvements. For example, raw contours generally require smoothing before placement on a map. Cartographic contours must also conform to certain spatial/logical rules; for example, contours may not cross waterbodies. The objective was to create contours that match as closely as possible the cartographic contours produced by manual methods on the 1:24,000-scale, 7.5-minute Topographic Map series.

This report outlines the basic approach, describes a variety of problems that were encountered, and discusses solutions. Many of the challenges described herein were the result of imperfect input raster elevation data and the requirement to have the contours integrated with hydrographic features from the National Hydrography Dataset (NHD).
\end{abstract}

\section{Introduction}

The U.S. Geological Survey (USGS) is collaborating with Federal, State, and local partners to improve and deliver topographic information for the Nation. The webbased platform for this effort is The National Map (http:// nationalmap.gov/). A new generation of 7.5-minute mapsbranded as USTopo (http://nationalmap.gov/ustopo/index. $h t m l$ ) - is being created as a set of downloadable GeoPDFs ${ }^{\circledR}$. A fundamental base layer on USTopo products is digital topography, shown as contour lines. This report begins by describing the original process for generating the first USTopo contours, then moves on to enhancements that were added for the production of contours for The National Map online viewer (http://viewer.nationalmap.gov/viewer/). As with any large-scale endeavor, creating an acceptable nationwide dataset comes with accompanying problems and issues. A basic workflow and examples of problems and solutions are presented.

\section{Characteristics of the Contour Generation Process}

- The process is fully automatic. National Hydrography Dataset (NHD) layers are edited when necessary, contours are not.

- The process is repeatable.

- The output data are Geographic Information SystemGIS-ready, available as zipped file geodatabases.

- The dataset offers complete coverage of the conterminous United States (CONUS).

- The contours are spatially consistent between quads.

- The contours are high resolution (surface interpolation is done primarily at $1 / 27$ arc-second). Small features, which tend to be filtered out if a larger cell size is used, are retained (fig. 1).

- The contours are produced by a single method.

- The contours represent the approximate level of detail in 7.5-minute topographic quadrangles.

- Elevation data are modified to more closely conform to appropriate NHD waterbody, area, and flowline features.

- The processing unit is $7.5^{\prime} \times 7.5^{\prime}$, corresponding to traditional USGS topographic quadrangles.

\section{Cartographic Rules for Digital Contours}

The following cartographic rules were followed as closely as possible:

- Contours should cross double-line streams at right angles (fig. 2). 


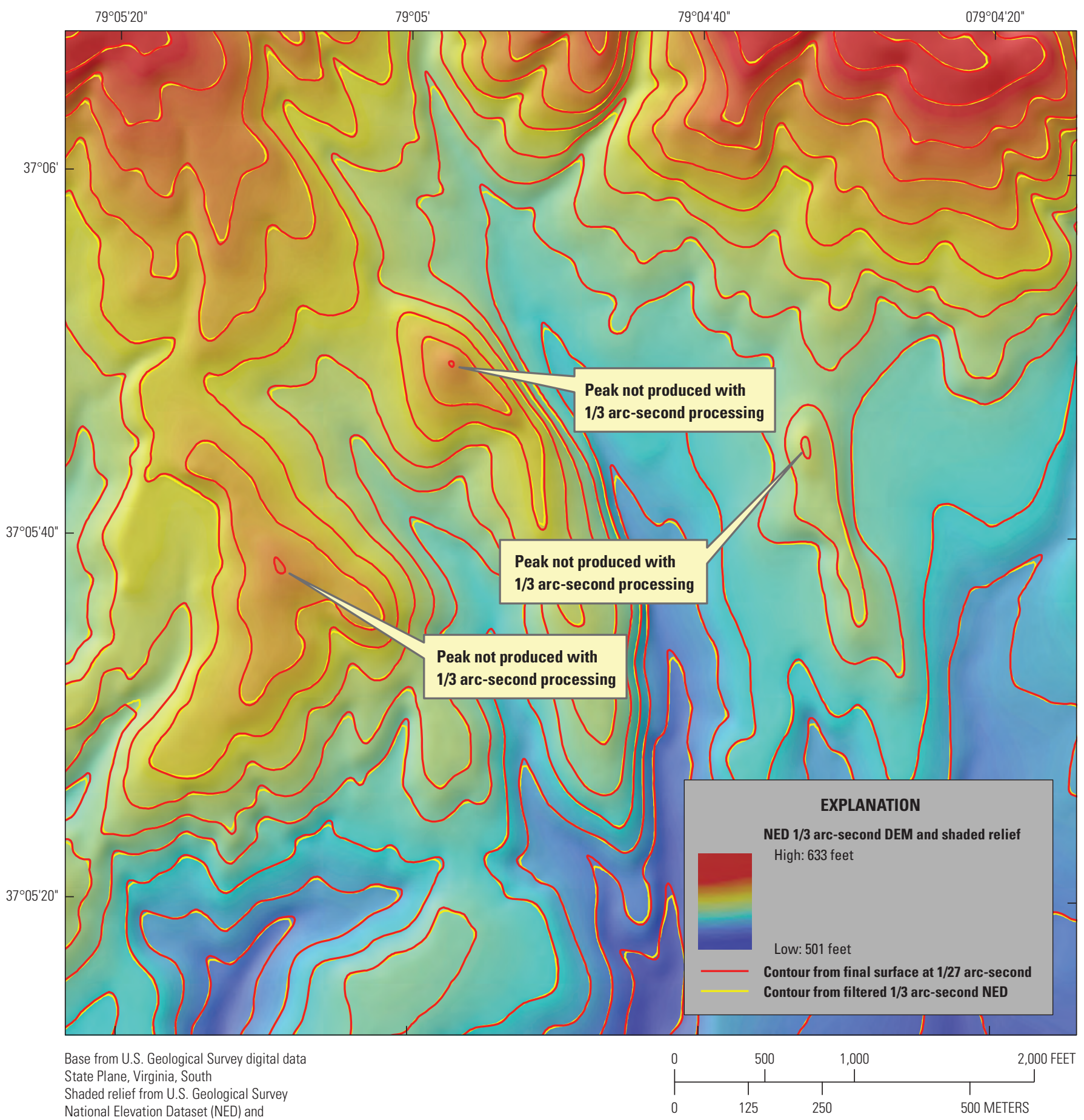

National Elevation Dataset (NED) and

Digital Elevation Model (DEM) data

North American Datum of 1983 (NAD 83)

LONG ISLAND, VIRGINIA

CONTOUR INTERVAL 10 FEET

NORTH AMERICAN VERTICAL DATUM OF 1988

2011

Figure 1. Small contours that are retained by interpolating at a cell size of $1 / 27$ arc-second. 


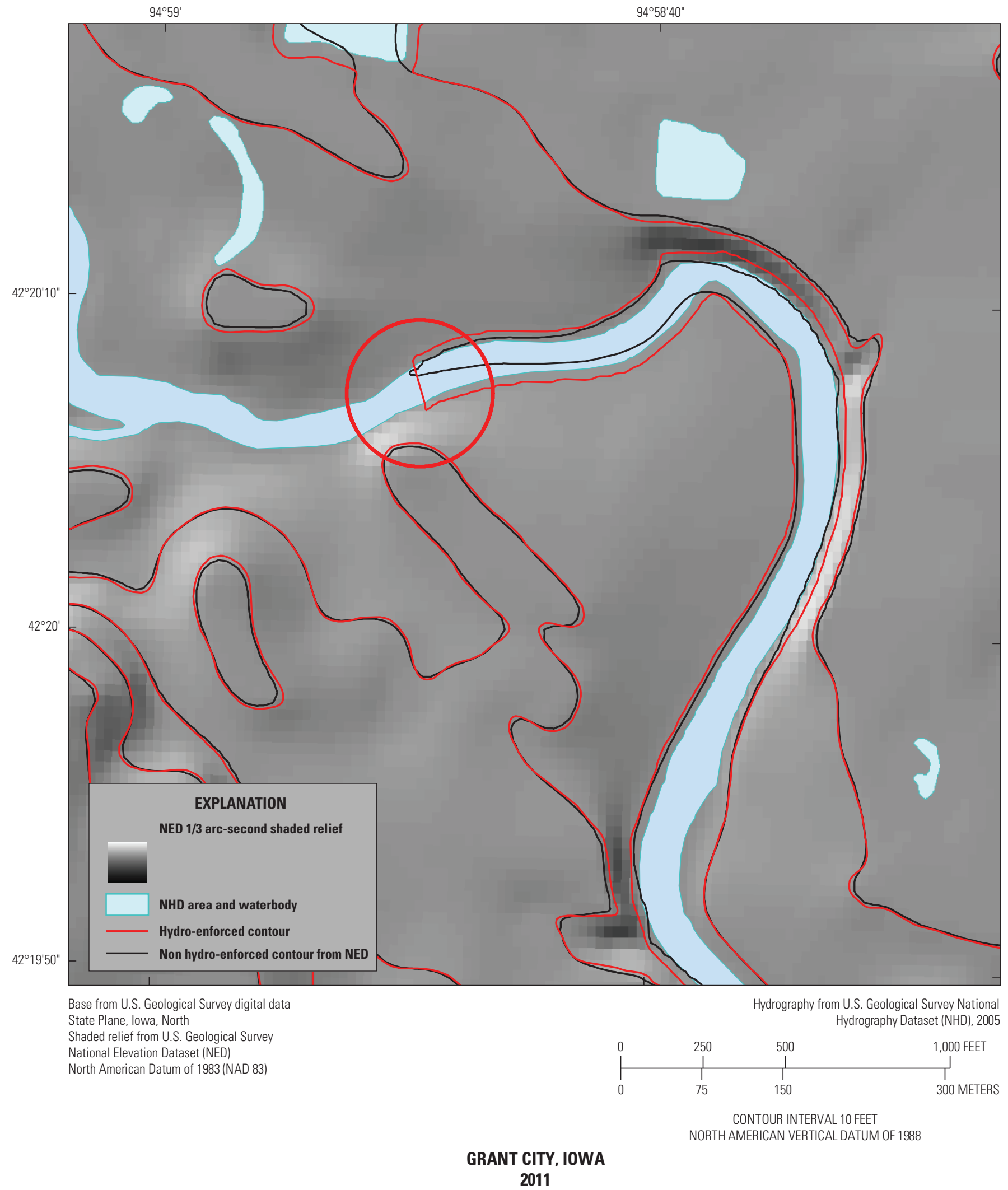

Figure 2. How hydro-enforcement has improved the contours so they cross the river correctly at an approximate right angle. 
- Contours may not cross waterbodies.

- Contour crenulations should conform to reentrants (fig. 3).

- Depression contours should not cross single-line streams more than once.

- The contour interval for a quad is the larger of the interval used on the 1:24,000-scale, 7.5-minute Topographic Map series and the minimum statistically supportable interval as based on characteristics of the underlying National Elevation Dataset (NED) data.

- Contours may pass through swamps.

- Contours may pass through small, tightly grouped hydrographic features, such as sewage lagoons.

- All elevations are expressed in feet. All elevation values (and the resulting contour lines) were cast on the North American Datum of 1983 (NAD 83) horizontal datum and the North American Vertical Datum of 1988 (NAVD 88) vertical datum.

\section{Practical Considerations}

- Although it would be preferable to enforce the elevation surface with single-line canals, this method is avoided because canals in the NHD sometimes do not consistently flow downhill. In some areas, the spatial complexity and density of canals can negate their usefulness in influencing the new intermediate elevation surface.

- Double-line canals are withheld as input to the enforcement process for the same reasons as singleline canals. Additionally, double-line canals that are close to double-line streams (particularly canals that are parallel to double-line streams and of a different surface elevation) are problematic when generating flat river surfaces using the Inverse Distance Weighted (IDW) interpolator.

- To make a nationwide, consistent set of contours, the decision was made to modify the elevation surface to conform as closely as possible to features in the NHD, even when the NED data are newer than the NHD. NHD feature geometries are not modified to conform to more recent NED data because of the intractable nature of automating the workflow; for example, culverts are not represented in light detection and ranging (lidar) data, and subsequent dam formation in the elevation raster can create unwanted waterbodies.

\section{Limitations of the Contour Dataset}

It can be advantageous to describe a project or product in negative terms because this is the type of information commonly left unstated and the reader is left to determine limitations by deduction or other means, which is a frustrating exercise.

- The output contours are not part of an official USGS dataset or product, and they are not part of the current contours made for the USTopo GeoPDF maps. The output contours are the result of a scientific research project.

- The output contours are not engineering contours. They are but one of a myriad of possibilities in the quest to represent topography. More accurate contours (those that conform better to the original NED surface) can be produced, but they will lack the smoother appearance of these cartographic contours and are not as likely to match NHD features.

- Although one of the overall goals of the project is to create contours that mimic those shown on 1:24,000scale, 7.5-minute Topographic Maps, this cannot be done to perfection. In fact, a perfect match is impossible because digital contours are based on newer, more accurate horizontal and vertical datums than topographic maps (fig. 4).

- The dataset is visually seamless at small scales except for discontinuous contour intervals between quads; however, edge-matching and joining of features across quad boundaries (C. Frye, oral commun., 2009) were not attempted.

- Zero-elevation contour lines near the oceans were deleted. This was a practical way of dealing with imperfect NED data along the coastline, as well as eliminating confusion or conflicts with any shoreline datasets of the National Oceanic and Atmospheric Administration (NOAA).

- The contours are not intended to be appropriate for every conceivable purpose; for example, users may require a different contour interval or metric units.

- No attempt was made to regionalize contour intervals to prevent a checkerboard appearance (fig. 5).

- No attempt was made to integrate the contours with imagery.

- There are no plans to update the contours.

- It should be noted that the NED and the NHD are updated on an ongoing basis. This makes direct comparisons with contours of other vintages potentially problematic. 


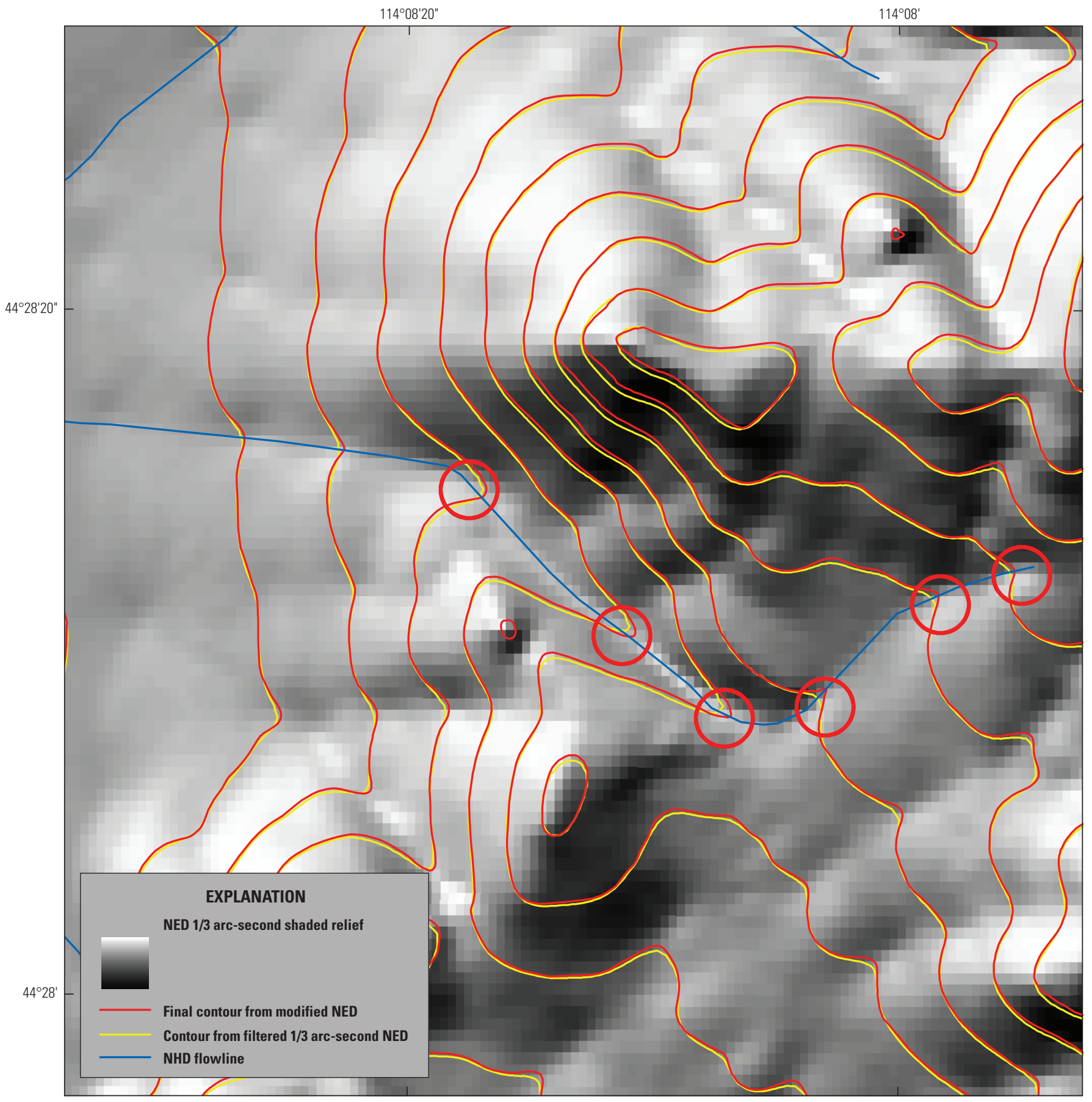

Base from U.S. Geological Survey digital data State Plane, Idaho, Central

Hydrography from U.S. Geological Survey Nationa

Shaded relief from U.S. Geological Survey

National Elevation Dataset (NED)

North American Datum of 1983 (NAD 83

Hydrography Dataset (NHD), 2009

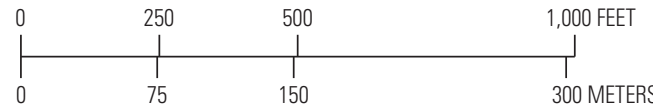

CONTOUR INTERVAL 40 FEET

NORTH AMERICAN VERTICAL DATUM OF 1988

\section{BRADBURY FLAT, IDAHO \\ 2011}

Figure 3. Reentrant contours with improved crenulations, which are indicated by red circles. 


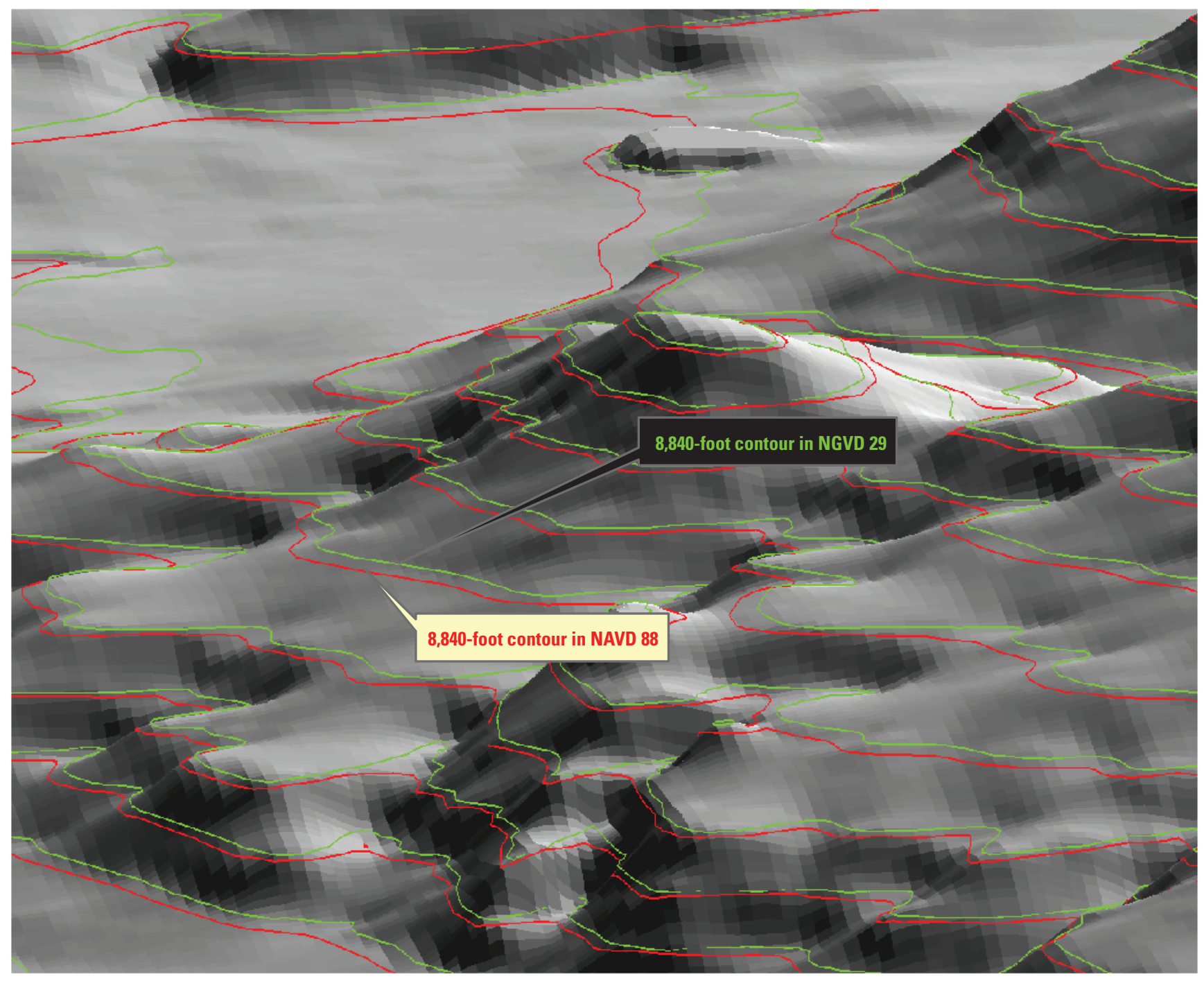

Figure 4. The effects on contours generated from elevation data referenced to the National Geodetic Vertical Datum of 1929 (NGVD 29) and the North American Vertical Datum of 1988 (NAVD 88). In the Creede, Colo., quadrangle, the difference between the two datums is 1.667 vertical meters. 


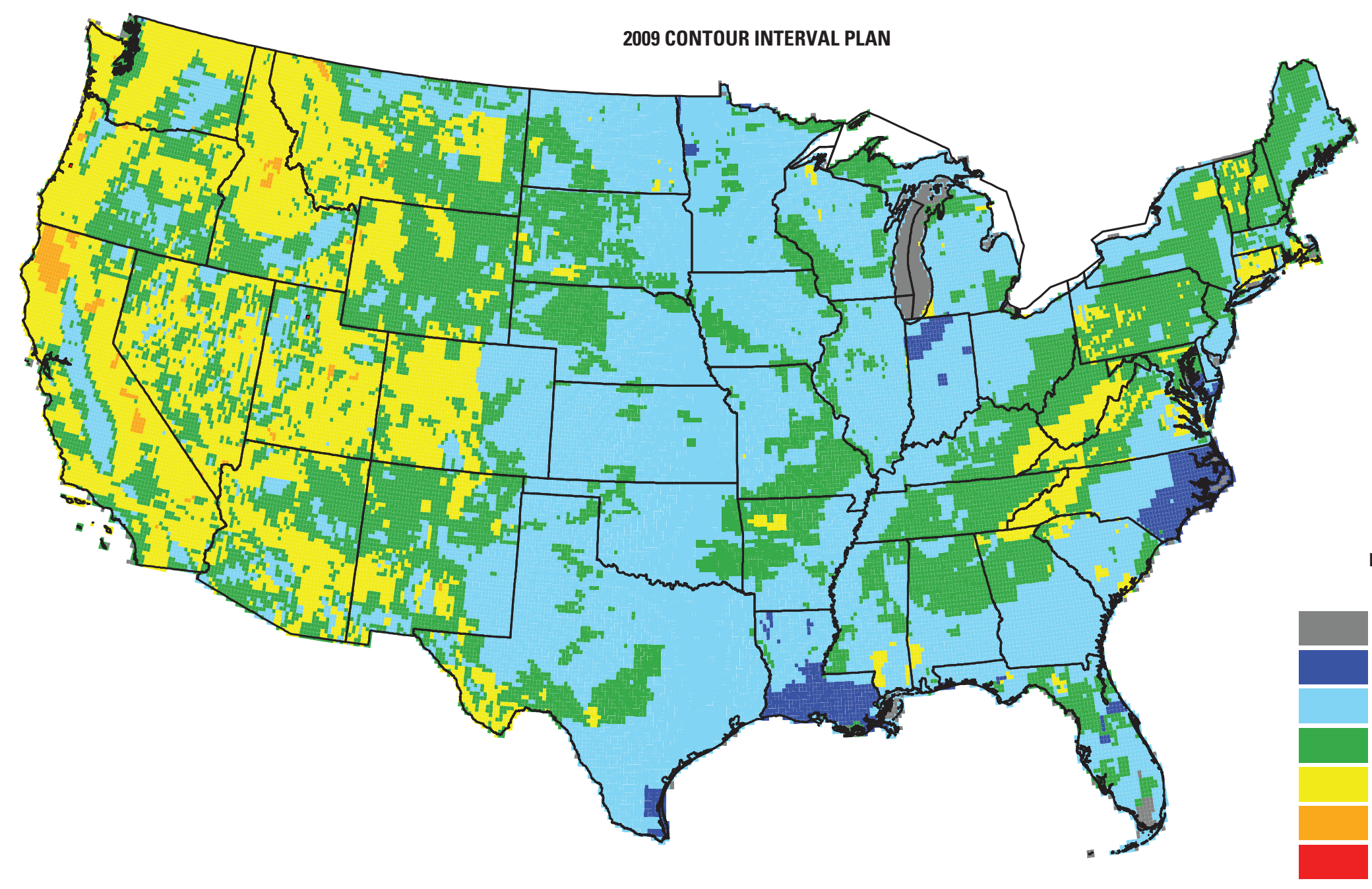

EXPLANATION

Contour intervals-In feet

Figure 5. Contour Interval Plan based on statistical analysis of February 2009 National Elevation Dataset (NED). 
- The intermediate elevation rasters from which the contours were generated were not archived because of inadequate disk space and limited usefulness of the highly modified surfaces (fig. 6).

\section{Required Input Data}

- NED 1/3 arc-second raster layer-A decision was made by consensus of several stakeholders in the USGS to use the $1 / 3$ arc-second (10-meter) layer of NED exclusively for the purpose of creating the USTopo 1:24,000 digital map series. This layer of the NED consists primarily of 10-meter source Digital Elevation Models (DEMs); however, about 12 percent of CONUS is covered by higher resolution data technologies such as lidar, and where they are available, they are sub-sampled to allow insertion into the NED 1/3 arc-second layer. Where neither 10-meter nor higher resolution data are available, 1 arc-second (30-meter) or coarser data are used.

- NHD vector data-All layers are high-resolution.

- Flowlines

- Streams/rivers

- Artificial paths

- Areas

- Streams/rivers

- Waterbodies

- Lakes/ponds and reservoirs

- Pre-processed by attaching the following elevation statistics to each feature

- Minimum elevation

- Maximum elevation

- Mean elevation

- Standard deviation

- Disconnected streams (derived in advance)

- USGS 7.5-minute quadrangle polygon dataset with pre-calculated contour interval and units.

\section{Input Data Quality Issues}

The process of contour generation would be fast and easy if all input data were perfect. Unfortunately, there are a number of known issues with the NED, as well as with the NHD, that must be dealt with as part of contour generation. The most challenging aspect of automatically creating acceptable contours for large areas is developing algorithms to solve (or at least ameliorate) any issues with input data or adherence to digital cartographic rules.

\section{Data Quality Issues in the NED}

The usability of the NED as the primary input source for creating contours depends on five factors:

- The source data used to generate the NED. In general, higher resolution elevation source data for NED are better as input to the contour generation process; however, other factors may be more important for contour generation. For example, lower resolution elevation data containing flattened water may provide a basis for better contours than higher resolution data that have Triangulated Irregular Network (TIN) artifacts in streams.

- Production method (Maune, 2007)

- Cell size

- Terrain characteristics

- Date of DEM creation

It is even more important, however, to identify and address various types of errors and artifacts in the DEMs and subsequently the NED. In some cases, the cause of a given error or artifact is known or can likely be deduced, whereas in other cases the cause is unknown. Because error handling must be addressed when feasible, it is also important to try to understand the characteristics of an error based on examination of the data.

\section{Examples of Errors and Artifacts in the NED}

- Triangulated Irregular Network (TIN) artifacts can appear in the NED (fig. 7) during light detection and ranging (lidar) processing if breaklines are not used to flatten water. These are mitigated in the river and waterbody surface generation steps.

- Some quads had spurious, crenulated contours that survived in flat areas despite the generalization of the elevation data and output contours. This is referred to informally as "wormwood." These were mitigated somewhat by slightly terracing the elevation raster, rounding to the nearest tenth of a foot (fig. 8). 


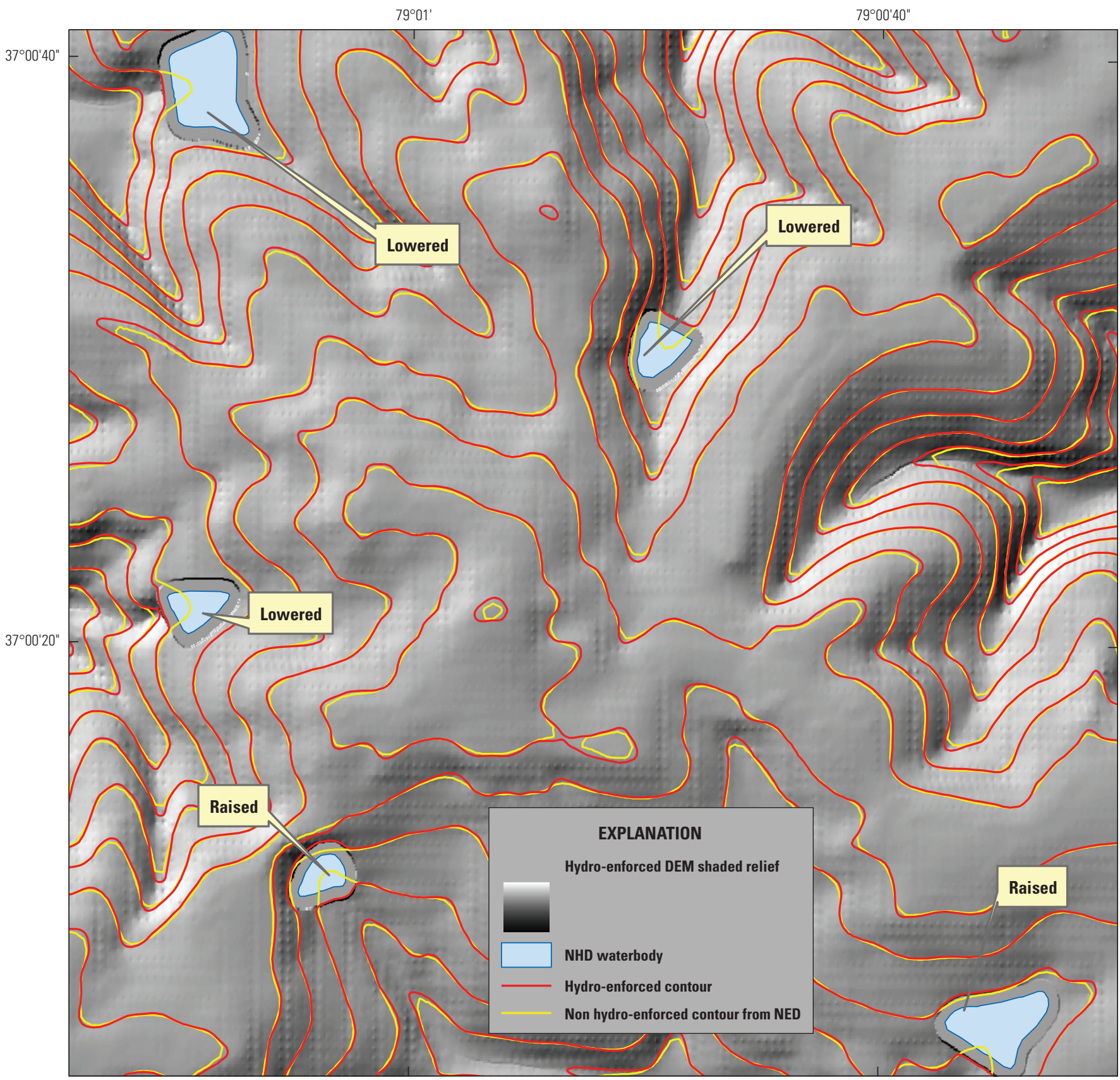

Base from U.S. Geological Survey digital data

State Plane, Virginia, South

Shaded relief from U.S. Geological Survey

National Elevation Dataset (NED) and

Digital Elevation Model (DEM) data

North American Datum of 1983 (NAD 83)

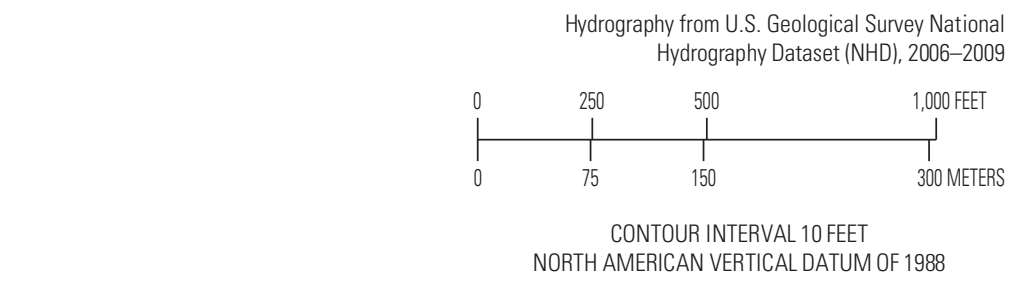

LONG ISLAND, VIRGINIA

2011

Figure 6. Results of routing contours around waterbodies by changing the surface elevation of each waterbody. 

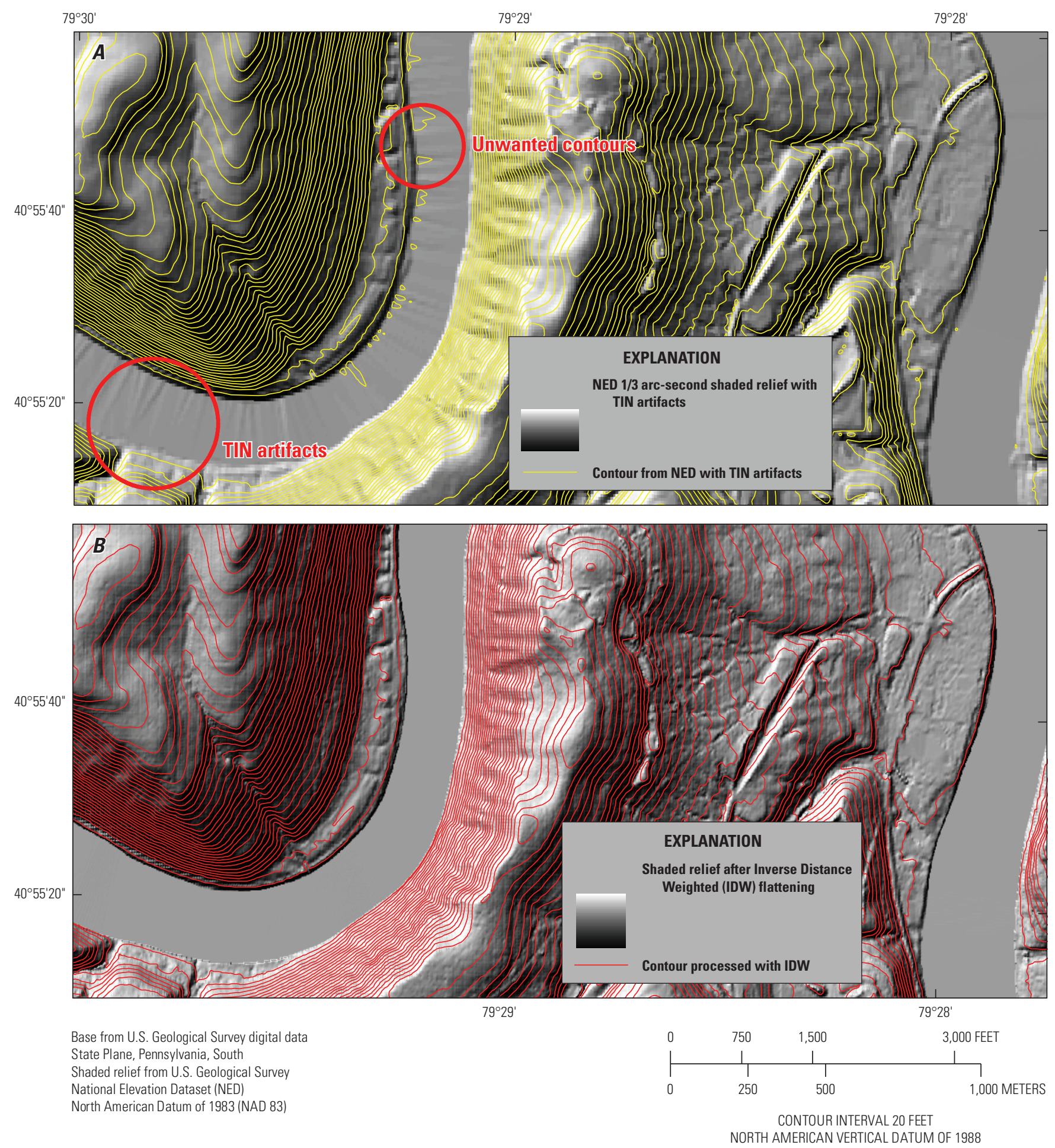

TEMPLETON, PENNSYLVANIA

2011

Figure 7. A, Triangulated Irregular Network (TIN) artifacts in the river distort the water surface in the National Elevation Dataset (NED), resulting in spurious contours in the river. $B$, Improved contours in relation to the river channel after removal of TIN artifacts. 


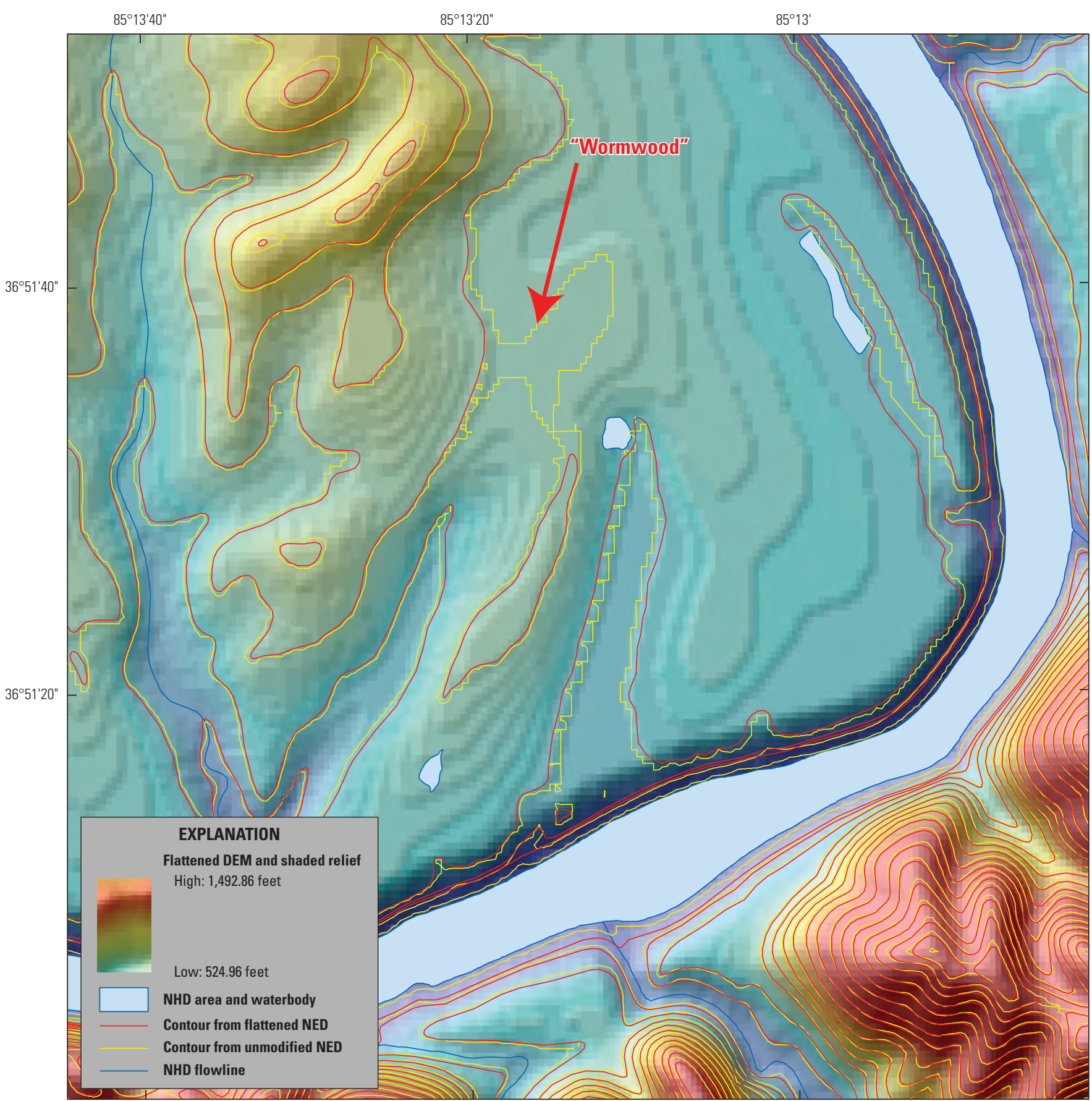

Base from U.S. Geological Survey digital data State Plane, Kentucky, South

Shaded relief from U.S. Geological Survey

National Elevation Dataset (NED) and

Digital Elevation Model (DEM) data

North American Datum of 1983 (NAD 83)

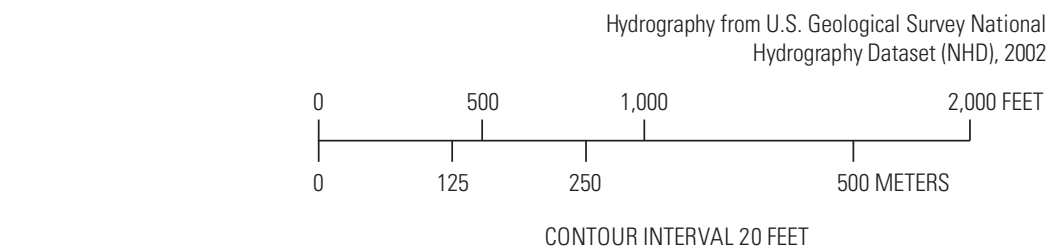

CONTOUR INTERVAL 20 FEET

NORTH AMERICAN VERTICAL DATUM OF 1988

WOLF CREEK DAM, KENTUCKY

2011

Figure 8. Example of flattening a Digital Elevation Model (DEM) to alleviate "wormwood." The DEM and shaded relief rasters were highly exaggerated for the purpose of illustration. 
- River channels are not always present or adequately defined in the NED (fig. 9). This is handled by creating a new elevation surface to represent the river surfaces using IDW interpolation.

\section{Examples of Errors and Problems in the NHD}

- The digitized direction of flowlines is inconsistently correct in NHD (fig. 10). The interpolation tool requires the flow direction to be correct and in agreement with NED to properly modify the new raster surface so the reentrants conform to the flowline channel. Flowlines are flipped programmatically when the direction is incorrect. To determine whether a flowline is correctly oriented, the elevations of the beginning and ending nodes are retrieved and compared. A difference threshold of $2 \mathrm{~m}$ is adequate in most cases. Flowlines that flow over hills, essentially making the line incorrect in both directions (fig. 11), are flagged and removed from the interpolation process.

- Features are stored in an incorrect NHD layer; for example, reservoirs should be in the waterbody layer, but occasionally they appear in the area (doubleline streams, etc.) layer. Because the processing of waterbodies (flat and level) and double-line streams (generally flat but not level) are handled differently, this will result in unacceptable contours.

- Features may be stored in the correct NHD layer but possess incorrect feature code (FCode) values. There are two types of coding errors. The first type is when the code is actually appropriate for the NHD schema, but the underlying topographic feature behaves in a manner that results in inaccurate contours. The second situation occurs when the FCode values are incorrect, as intended in the NHD schema; for example, if an estuary is coded as a double-line stream, that will result in unacceptable contours.

- Tributaries are not always digitized as separate polygons from a higher order river in the areas NHD layer. Although this is not an error in the polygons as far as cartographic uses are concerned, it can cause highly visible errors in the output contours.

\section{Pre-Processing Steps}

Any processing that can be done before generating contours for a quad will save time. Because many NHD features will be used more than once because of overlaps in processing extents, duplicate processing can be avoided by pre-processing these features just once.

- Compute minimum, maximum, mean, and standard deviation of the elevation for each waterbody and store the values with the waterbody polygon attributes. These values are used to determine whether a waterbody needs to be raised or lowered to avoid having a contour cross it.

- Create a layer of disconnected streams from the NHD flowlines. The disconnected streams are used as an overlay that will prevent the software from deleting depressions that intersect them.

\section{Processing Steps}

Many of the following steps or sections could be executed asynchronously; for others, the order of execution is critical.

- Select a polygon representing a 7.5-minute quadrangle.

- Buffer the polygon by 10 percent for better edgematching and greater likelihood of obtaining polygon closure, as is required for depression identification.

- Extract NED raster using the buffered polygon as the processing extent.

- Convert NED to points. The spacing of these points is $1 / 3$ arc-second and will be used as the primary input to the interpolation process. The interpolation is accomplished by executing the Environmental Systems Research Institute's geographic information system software (ArcGIS) TopoToRaster tool. The interpolated surface is created with a cell size of $1 / 27$ arc-second. For a comparison of processing at varying cell sizes, refer to figure 12. It is counterintuitive, but this relatively sparse set of points is more effective in generating acceptable high-resolution contours than a more dense set of points (Environmental Systems Research Institute, 2012).

- Extract the NHD areas (double-line streams) within the buffered polygon.

- Extract the NHD flowlines within the buffered polygon. Artificial paths are extracted separately from the single-line streams.

- Determine if any of the flowlines are incorrectly flowing uphill and flip if necessary.

- Run the ArcGIS TopoToRaster Tool. The inputs are the converted NED points and the NHD flowlines. The optimum number for the Iterations parameter is five (fig. 13). Memory limitations require that a 

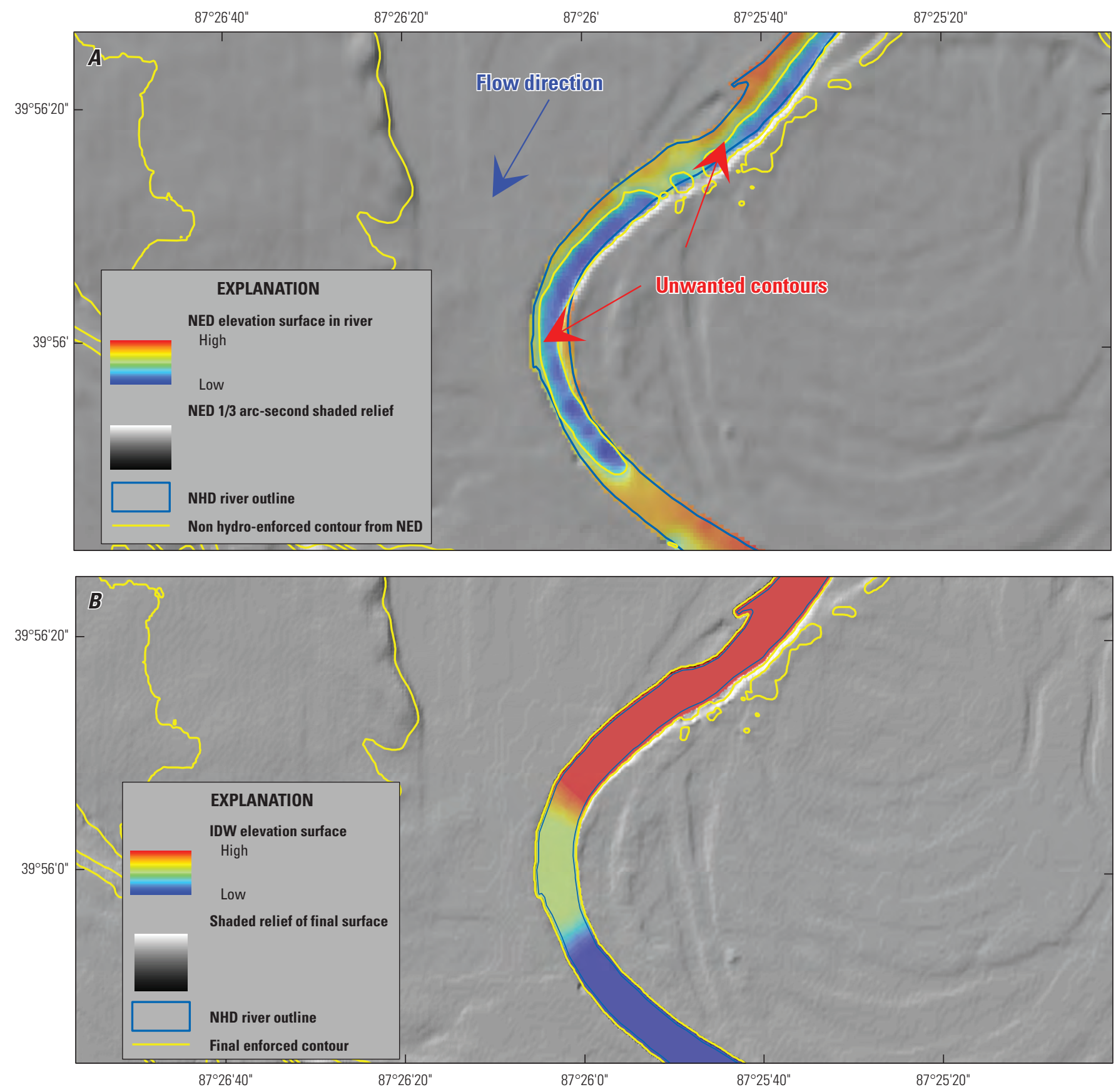

Base from U.S. Geological Survey digital data

State Plane, Indiana, West

Shaded relief from U.S. Geological Survey

National Elevation Dataset (NED)

North American Datum of 1983 (NAD 83)

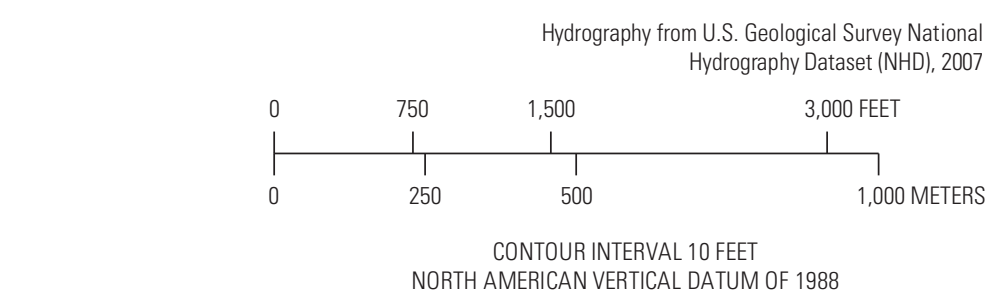

\section{NEWPORT, INDIANA}

2011

Figure 9. A, A poorly defined river channel in National Elevation Dataset (NED), with associated inaccurate contours. $B$, The river channel and improved contours after Inverse Distance Weighted (IDW)-interpolation treatment. 

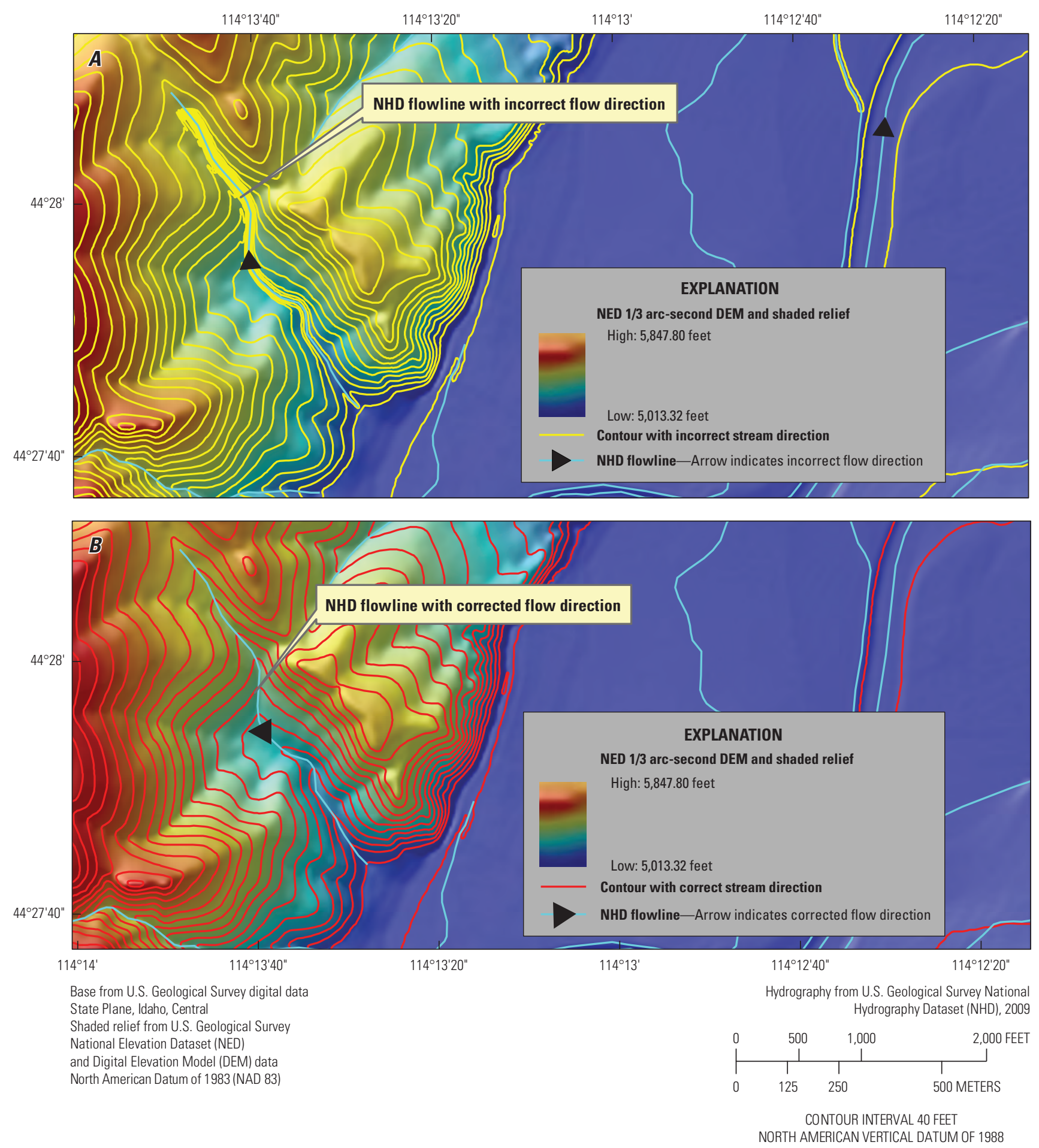

BRADBURY FLAT, IDAHO

2011

Figure 10. A, A National Hydrography Dataset (NHD) flowline that was digitized incorrectly so it flows uphill. $B$, Good reentrant contours obtained by reversing the order of vertices in the flowline. 


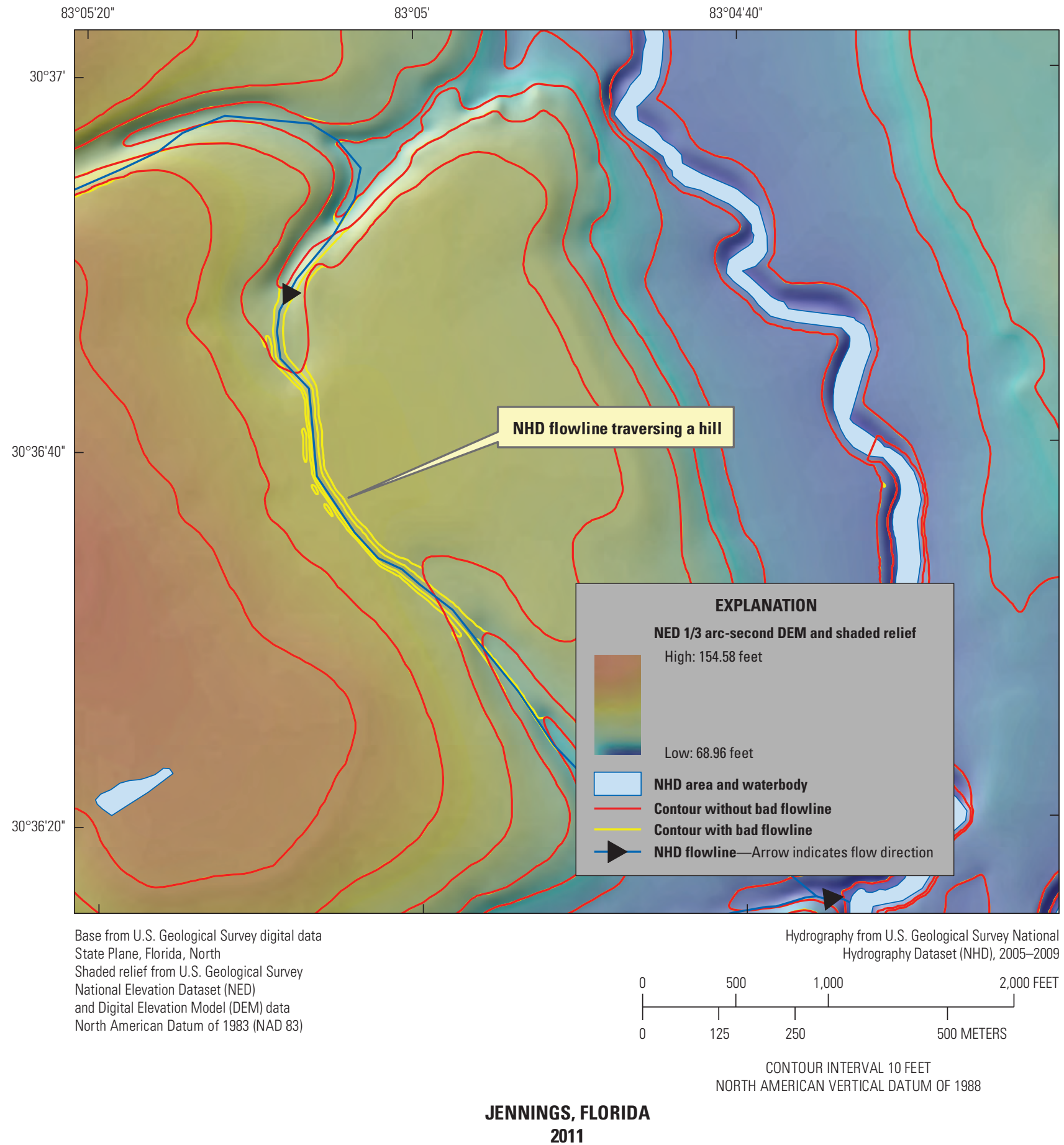

Figure 11. Incorrect contour representation, caused by a National Hydrography Dataset (NHD) flowline traversing a hill. 


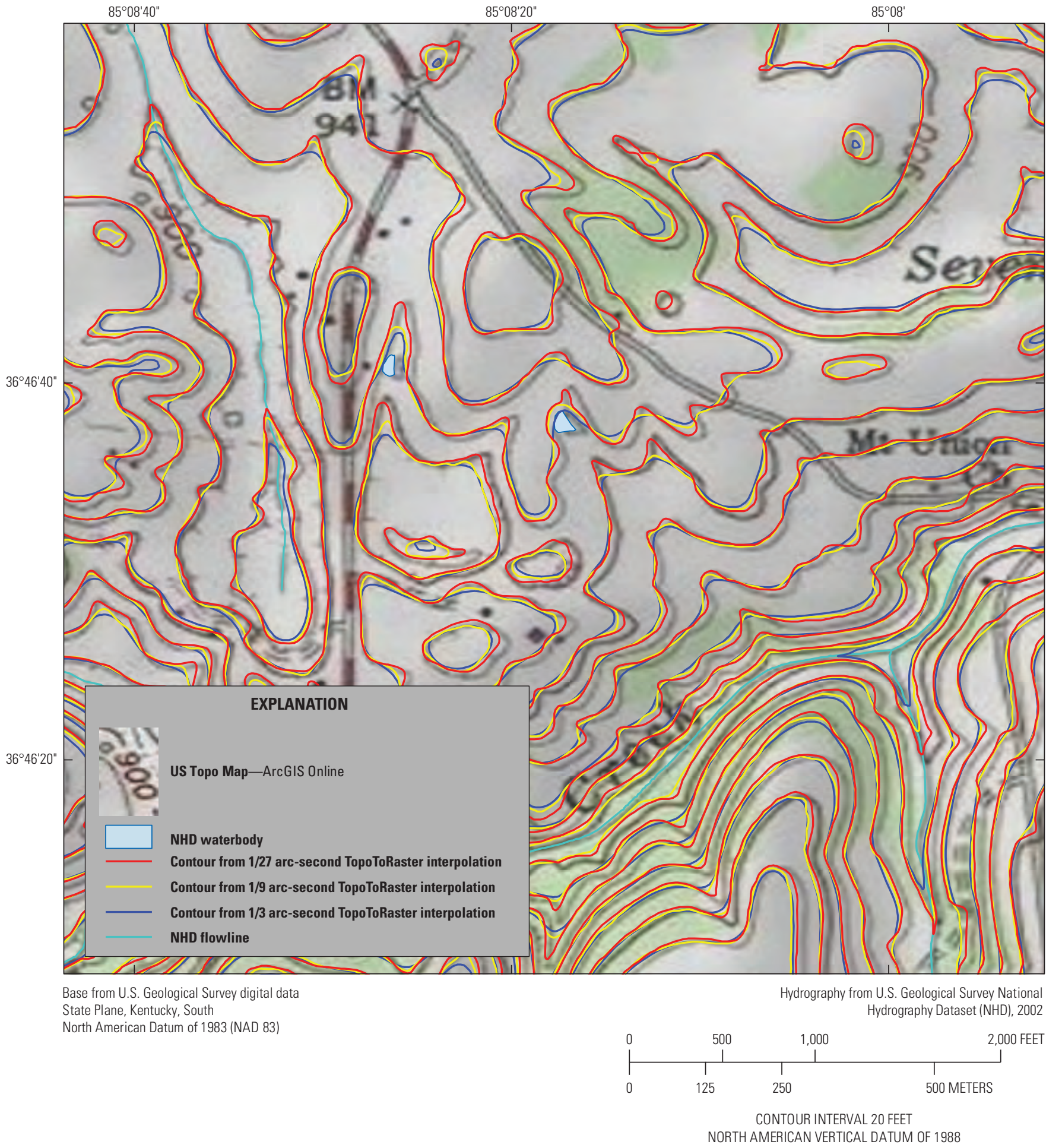

WOLF CREEK DAM, KENTUCKY

2011

Figure 12. The advantage of interpolating the new elevation surface at a cell size of $1 / 27$ arc-second — crenulations are tighter and the shapes of subsequent contours more closely conform to those on the original topographic map of this quadrangle. 


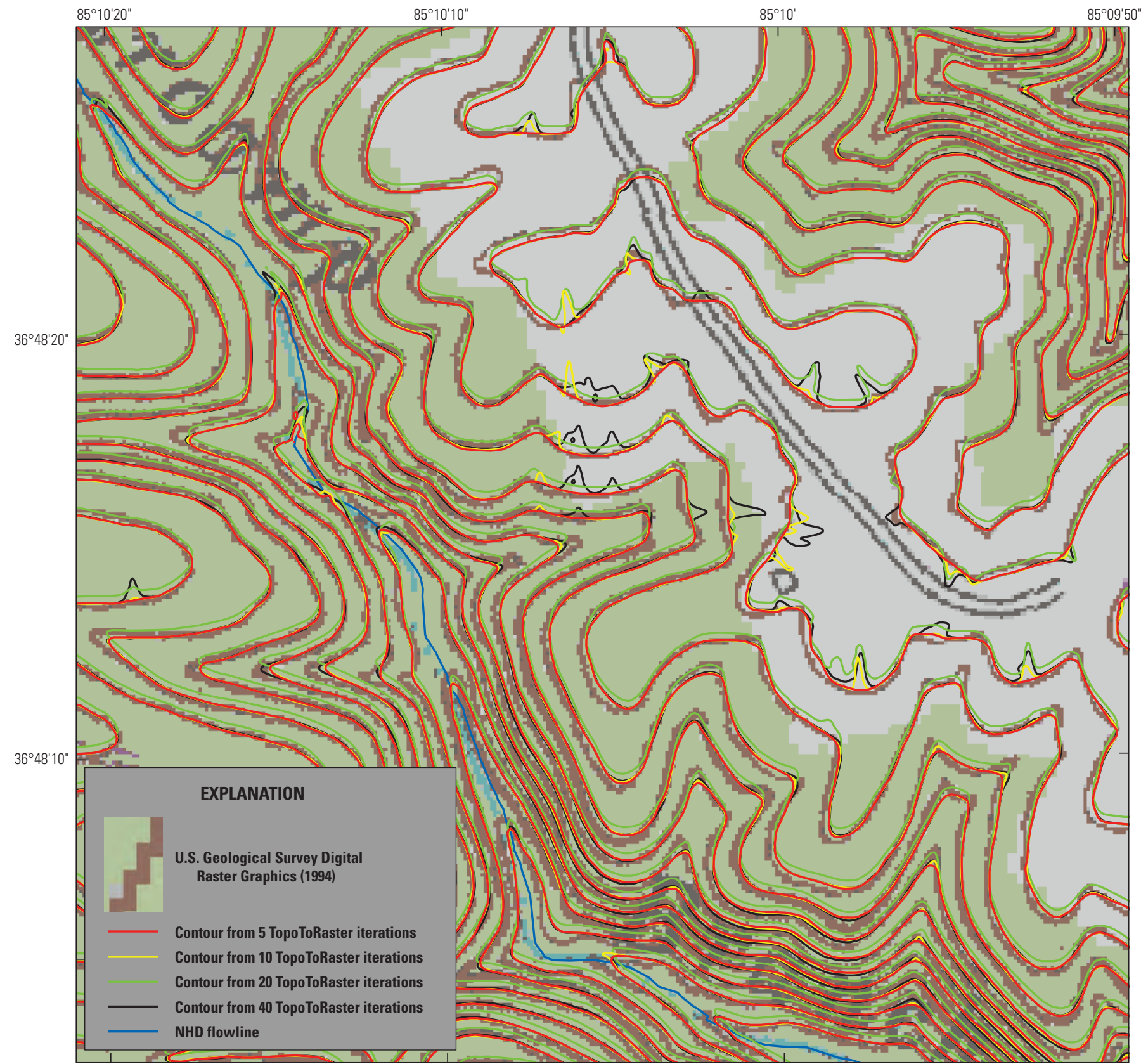

Base from U.S. Geological Survey digital data

State Plane, Kentucky, South

North American Datum of 1983 (NAD 83)

Hydrography from U.S. Geological Survey Nationa Hydrography Dataset (NHD), 2002

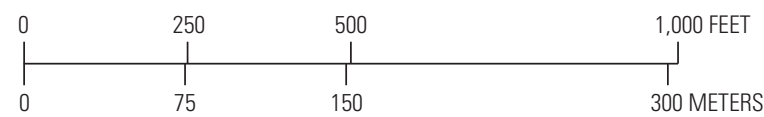

CONTOUR INTERVAL 20 FEET

NORTH AMERICAN VERTICAL DATUM OF 1988

WOLF CREEK DAM, KENTUCKY 2011

Figure 13. Contours as generated from four variations of TopoToRaster. Five iterations of TopoToRaster were determined to be the best for contour generation. 
quad be subdivided to allow multiple executions of TopoToRaster, in this process there are 36 tiles.

- Mosaic the 36 TopoToRaster output grids.

- Extract the NHD waterbodies within the buffered polygon. Exclude unwanted feature types such as swamps.

- Determine which waterbodies need to be raised or lowered to avoid containing a contour line, and determine what the new elevation of the waterbody should be. This is a complex issue because a given NHD waterbody may or may not be represented in the NED. If a deep reservoir is not represented in the NED, all of the NED values underneath the waterbody need to be raised, sometimes dramatically, to approximately the maximum elevation of the NED beneath the water polygon. In this case, the output contours will be forced to traverse near the face of the dam; however, if a waterbody is already represented in the NED (determined blindly by examining the elevation statistics beneath the water polygon to determine flatness), follow these steps.

- Filter the mosaic, using a $3 \times 3$ cell neighborhood to create a smoother surface.

- Generate temporary raw contours from the filtered grid.

- Simplify the temporary contours to reduce data volume.

- Intersect the temporary semi-raw contours with the waterbody to determine if any contour lines will cross the waterbody without adjusting the elevation of the waterbody.

- Loop through the waterbodies that intersect contours.

- Find the elevation of the contours that intersect the waterbody.

- Determine, based on the elevation statistics under the waterbody and the intersecting contour value, to what elevation the waterbody should be set (in raster form) to avoid having contours encroach upon it.

- Buffer the intersected waterbody polygons to ensure the final contours will not cross them. The buffer distances used are 0.0001234568 decimal degrees (four $1 / 9$ arc-second pixels) for isolated waterbodies, or 0.00004 decimal degrees for any waterbody polygon that is close to (within 0.000246912 decimal degrees) another waterbody (fig. 6)
- Convert the buffered waterbody polygons to a raster at $1 / 27$ th arc-second cell size, based on the newly designated elevation values.

- Create a separate elevation surface with IDW interpolation, which creates an output that replaces NED in the double-line streams. As a matter of expediency and consistency, all streams in all quads are processed, regardless of the quality or vintage of the underlying NED. The input points for the interpolation are extracted from vertices of the stream's artificial path, with corresponding elevation values harvested from the NED. In order to yield $\mathrm{z}$ values that are appropriate for surface generation, a "stepdown flattening" algorithm was developed (figs. 9, $14,15)$. The individual processing unit is a single reach or a group of connected reaches with the same Geographic Names Information System (GNIS) name. In concept, the grouping of artificial paths can be as simple as an Unsplit execution, using the GNIS name as an additional consideration. In practice, however, that is not always sufficient, because the terrain can be quite complex in localized areas, and the NHD area polygons are not always split at locations conducive to contour generation. It is beyond the scope of this paper to entail all the intricacies of this part of the processing.

- For each area polygon (for each set of artificial paths that together represent the centerline of a river reach):

- Densify the vertices in the artificial paths.

- Convert the densified artificial paths to points.

- Starting at the beginning (upstream) node of the reach (or first-order reach if more than one is being processed), assign the NED elevation value. For the second and subsequent points, follow these steps.

- Obtain the elevation for the point.

- Compare that elevation with the elevation of the previous (upstream) point. If the current elevation is greater than the previous elevation, assign the elevation of the previous point to the current point. Otherwise, leave the elevation of the current point as extracted from the NED.

- Merge all of the IDW interpolation input point datasets.

- Create a new elevation surface for the double-line streams using IDW interpolation. The output cell 


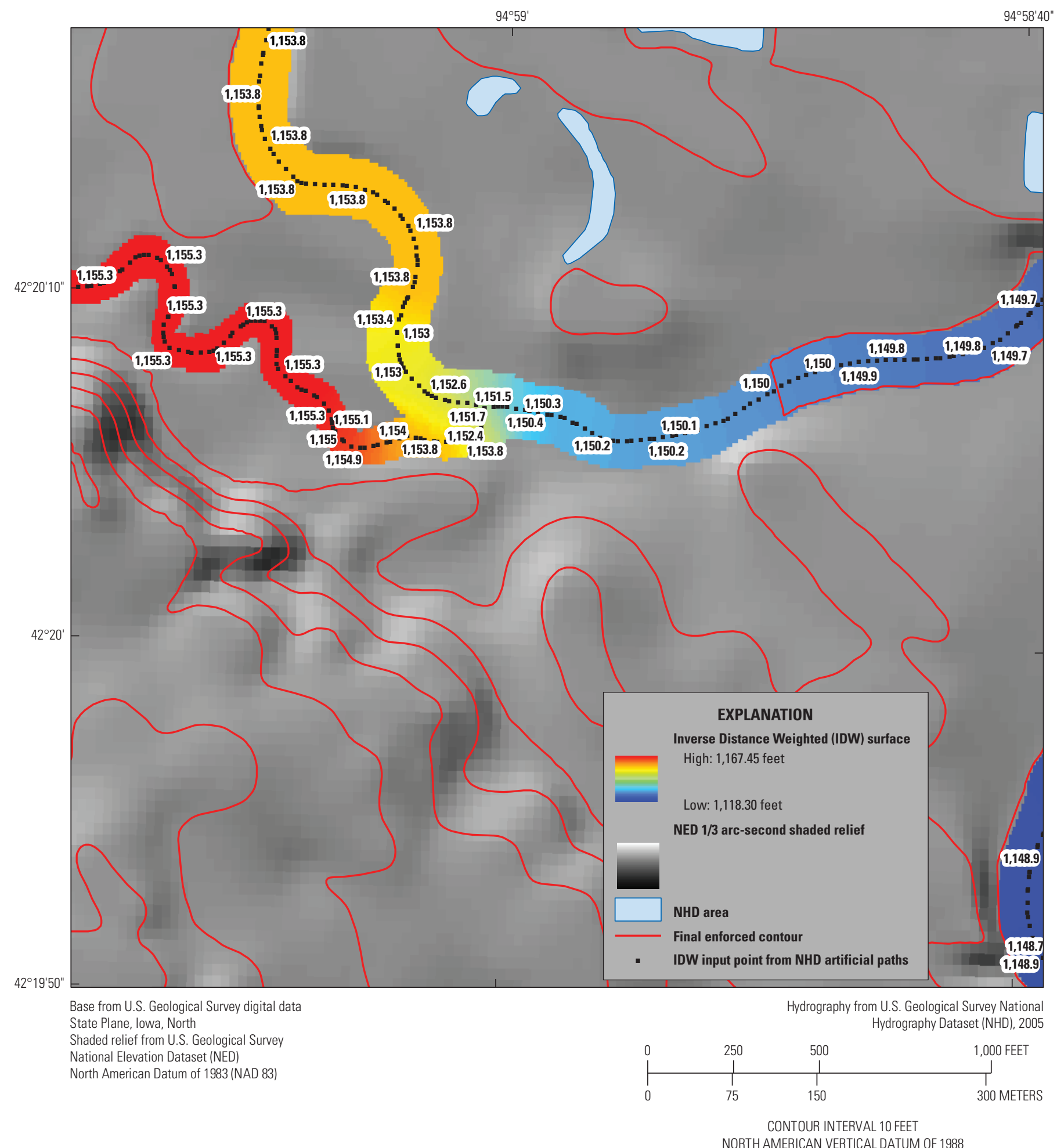

GRANT CITY, IOWA

2011

Figure 14. Final product after a new elevation surface is generated for the river. 


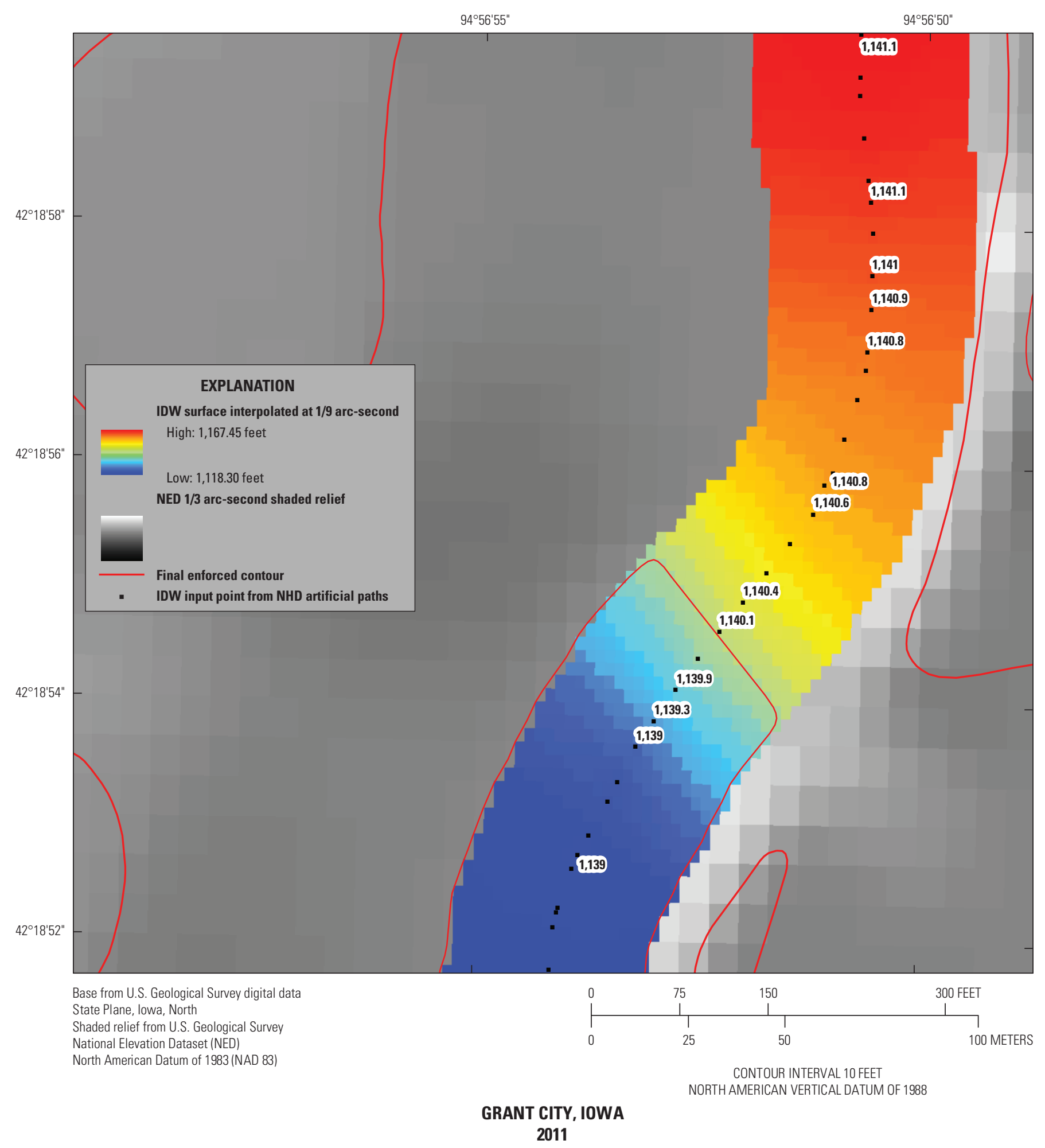

Figure 15. Zoomed-in view of a new river surface. Note the elevation values in the Inverse Distance Weighted (IDW)interpolated surface change in a perpendicular direction to the stream flow. 
size is $1 / 9$ arc-second, the Power parameter is set to 0.5 , and the Search radius is variable, with 12 points being specified for local influence.

- Buffer the area polygons by 0.0000925926 decimal degrees to provide a little more space between the contours and double-line streams.

- Mask the IDW-interpolated raster with the area polygons for the quad.

- Create the base elevation mosaic to be used for contour generation. The inputs are (in order of insertion into the new raster) the output from TopoToRaster, the IDW-interpolated mosaic, and the waterbody raster. Because the three input rasters have different cell sizes, the output cell size is specified as 1/27 arc-second.

- The following steps are used to flatten the elevation mosaic to the nearest tenth of a foot to avoid ending up with wormwood in the final contour datasets (fig. 8). All the steps are necessary, and they must be executed in the order listed to avoid an inferior output dataset.

- Multiply the elevation raster by 10 .

- Round the multiplied raster to the nearest integer value.

- Divide the integer raster by 10 .

- Filter the output of the division operation.

- Generate contours (ArcGIS Contour) from the previous raster. Even after the wormwood treatment, the contours can be visibly blocky and will have more vertices than is necessary to define the shapes appropriately.

- Simplify (SimplifyLine) the contours to reduce data volume. The Point Remove algorithm is used. The Maximum Allowable Offset is 0.000001 decimal degrees. This is necessary to allow the SmoothLine tool to complete. The input to SimplifyLine can be several hundred megabytes in size.

- Smooth (SmoothLine) the contours. The Polynomial Approximation with Exponential Kernel (PAEK) algorithm is used, with a tolerance of 0.0001 decimal degrees. Unfortunately, this increases the data volume.

- Simplify the smoothed contours, using the same SimplifyLine parameter as above, to reduce data volume (fig. 16).

- Process contours that are within double-line streams separately from those outside double-line streams.

- Clip out the contour features that are within the double-line streams into a separate dataset.
- Delete the same features from the original contour dataset, because they will be replaced.

- Simplify the arcs inside the river, using a large enough Maximum Allowable Offset ( 0.001 decimal degrees for narrow rivers, 0.01 decimal degrees for wider rivers) to collapse the contours into two-point (straight) lines.

- Append the collapsed contours within the rivers back into the original contours (fig. 2).

- The contour lines must be converted to polygons in order to determine which contours are depressions. The direction of each polygon determines if it is a depression.

- Use left/right polygon spatial logic to join the lines with the related polygons to transfer attributes from the polygons back to the arcs.

- Determine which line features are depressions based on the new polygon-derived attributes.

- Delete very small polygonal contours.

- Delete short depression contours that intersect with single-line streams.

- Delete depression contours that intersect with NHD artificial paths while saving those that intersect disconnected streams.

- Clip the contours back to the extent of the quad boundary.

- Add fields to the contour attribute table to retain information such as the contour interval and units (refer to appendix 1 for a listing and description of the fields). Update the fields as appropriate.

\section{Locate Potential Problems}

- Check for extra contours near areas.

- Determine the lowest elevation value from raw contours and output contours within a buffer of 0.0003 decimal degrees of each area polygon. Compare the number of contour dataset features in the polygon and the difference in contour value ranges of both contour sets in conjunction with the contour interval of the quad. Areas can be flagged for visual inspection by examining the relations of these numbers.

- Check for extra contours near waterbodies. 


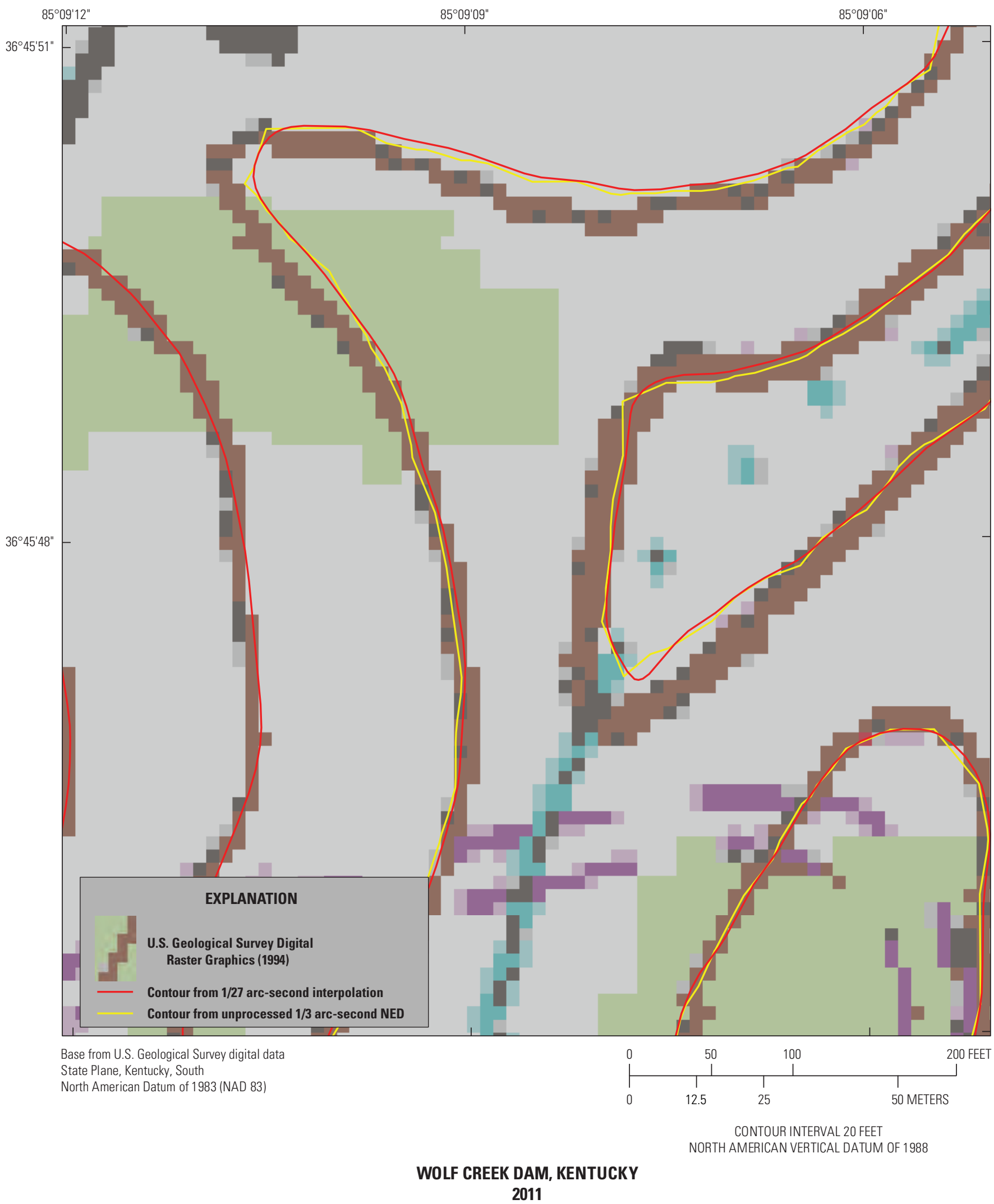

Figure 16. Contours generated from an unmodified National Elevation Dataset (NED) raster as well as fully processed contours. 
- Determine the lowest elevation value from raw contours and output contours within a buffer of 0.0003 decimal degrees of each waterbody polygon. Determine the number of raw and output contours within the buffer area. If the number of output contours in the buffer is greater than one, flag that waterbody for visual inspection. If the difference in the minimum contour values in the two datasets is greater than or equal to two times the contour interval, flag the waterbody for visual inspection.

- Check for extra contours near flowlines.

- The final contours are converted to points, a new surface is interpolated using those points, and a difference raster is created between the interpolated surface and the NED surface. The difference raster is converted to polygons. All difference polygons that have a value greater than three times the contour interval are selected. Flowlines that are within 0.0003 decimal degrees of any of the selected difference polygons are flagged for visual inspection.

- Inspect the contours in the areas near the flagged areas, waterbodies, and flowlines.

- Edit the NHD layers as determined during visual inspection.

- Regenerate contours for all affected quads.

- Perform final visual inspection to verify the problems were fixed.

\section{Post-Processing Steps}

- Combine the contours for all of the quads for a given state into a single file geodatabase.

- Delete zero-elevation contours near oceans.

- Identify depression contours by selecting all known depression features and finding any contours that connect to them (fig. 17).

\section{Resources Required}

- Each 7.5'x7.5' set of contours averages 1 to 2 hours of elapsed time to complete, depending on how many concurrent processes are run. In addition, the nature of the topography, as well as the characteristics of the NHD in a particular quad, contributes to the varying completion time. Approximately 53,804 datasets were produced.

- The primary computing resources consisted of 3 eightcore Windows Servers and 5 four-core Windows-based Virtual Machines. At the peak of the processing in the project, several desktop and laptop systems were made available by colleagues.

- ArcGIS, ArcGIS Server, and Python were the primary software tools used. The size of the completed set of contours for CONUS is estimated to be approximately 150 gigabytes.

\section{URL for Data Download}

The contours are available for downloading by visiting http://topotools.cr.usgs.gov/contour_data.php. The files are organized by State and are stored in zipped file geodatabases. States that have not been reviewed are not yet available.

\section{Contour Web Service}

A web-based contour generator (CONUS only) was developed to allow anyone to create basic contours and download them in shapefile format. User-specified parameters include area-of-interest, elevation source, contour interval and units, and index frequency. No hydro-enforcement is provided with this service. The output coordinate system is Geographic, NAD 83.

- http://topotools.cr.usgs.gov/XMLWebServices2/ USGS_Contour_Service.asmx?op $=$ getContours 


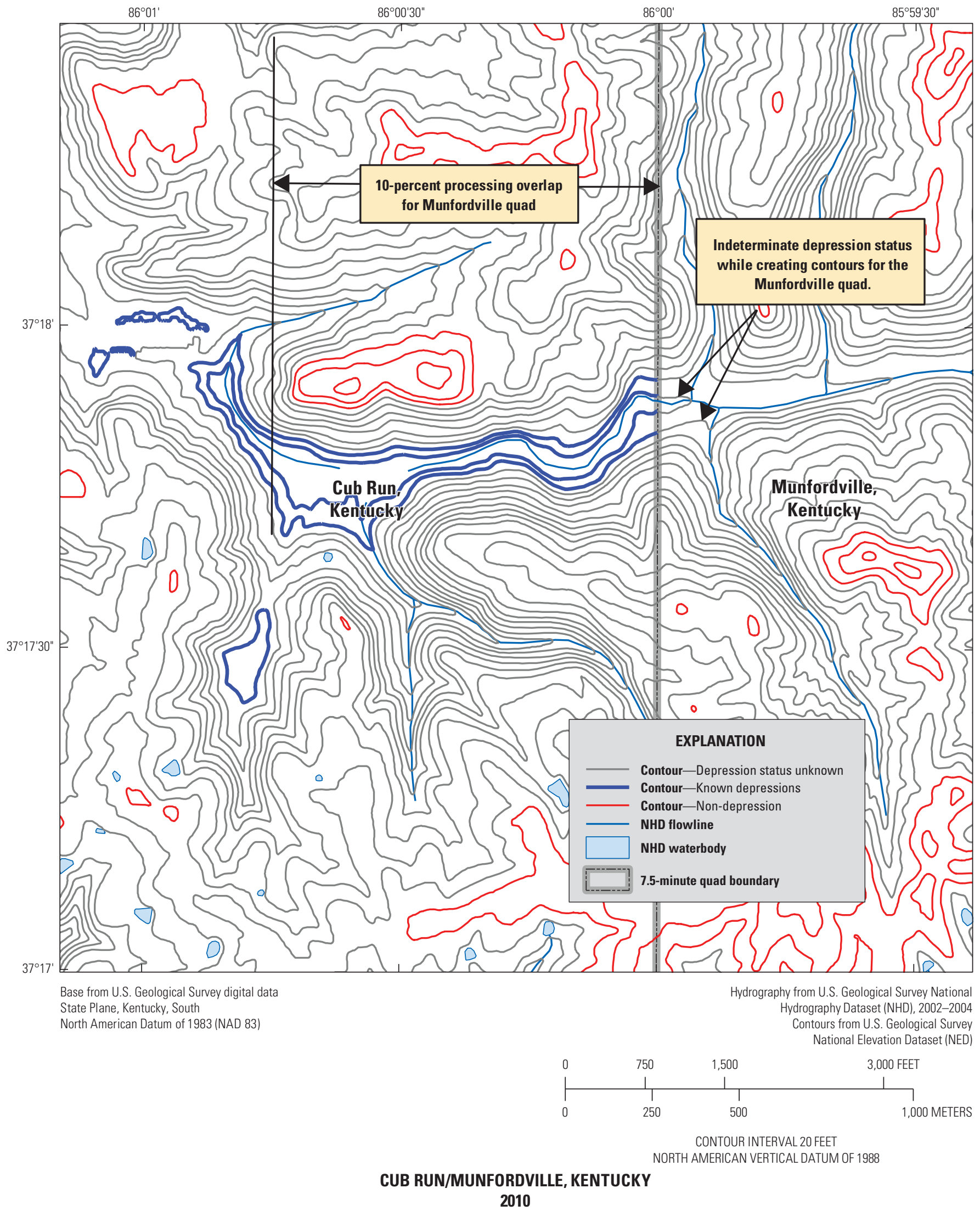

Figure 17. Large depressions, which are defined in post-processing by comparing attribute values on contours in adjacent quads. 


\section{References}

Environmental Systems Research Institute, 2012, Using the Topo to Raster tool, online ed., 6 p., accessed July 16, 2012, at $h$ ttp://webhelp.esri.com/arcgisdesktop/9.3/index.cfm?id $=36$ $14 \&$ pid $=3607 \&$ topicname $=U$ sing_the_Topo_to_Raster_tool.

Hutchinson, M.F. 1996, In Proceedings, Third International Conference/Workshop on Integrating GIS and Environmental Modeling, Santa Fe, N. Mex., January 21-26, 1996, Santa Barbara, Calif.: National Center for Geographic Information and Analysis, accessed at http://www.ncgia. ucsb.edu/conf/SANTA_FE_CD-ROM/sf_papers/hutchinson_ michael_dem/local.html.

Maune, D.F., Kopp, S.M., Crawford, C.A., and Zervas, C.E., 2007, Chapter 1-Introduction, in Maune, D.F., ed., Digital elevation model technologies and applications-The DEM user's manual ( $2 \mathrm{~d}$ ed.): Bethesda, Md., American Society for Photogrammetry and Remote Sensing, p. 99-118.
U.S. Geological Survey, 2012, Downloadable contours as described in this report, accessed July 16, 2012, at http:// topotools.cr.usgs.gov/contour_data.php.

U.S. Geological Survey, 2012, Contour generation web service, accessed July 16, 2012, at http://topotools. cr.usgs.gov/XMLWebServices2/USGS_Contour_Service. asmx? op $=$ getContours.

U.S. Geological Survey, 2010, National Elevation Dataset (NED): U.S. Geological Survey, accessed July 16, 2012, at http://ned.usgs.gov/.

U.S. Geological Survey, 2010, National Hydrography Dataset (NHD): U.S. Geological Survey, accessed July 16, 2012, at http://nhd.usgs.gov/.

U.S. Geological Survey, 2010, The National Map: U.S. Geological Survey, accessed July 16, 2012, at http:// nationalmap.gov/. 



\section{Glossary}

Area NHD polygons representing such features as double-line streams.

Flowline NHD single-line feature, such as linear streams and artificial flow paths.

Waterbody NHD lakes, reservoirs, and related polygonal hydrographic data. 

Appendixes 1-2 


\title{
Appendix 1. Contour Attributes Data Dictionary
}

\author{
OBJECTID \\ Shape \\ ContourElevation \\ ContourUnits \\ FCODE \\ Depression \\ CELL_ID \\ ProcessDate \\ MapID \\ NEDResolution \\ NEDDate \\ Shape_Length \\ Unique ID, arbitrarily assigned by ArcGIS software \\ Defines what type of geometry is in the feature class (line) \\ Elevation of each feature, expressed in ContourUnits \\ 1 = Feet $2=$ Meters (none in this dataset) \\ 10101 - Normal contour \\ 10102 - Normal index contour \\ 10104 - Depression contour \\ 10105 - Depression index contour \\ Interval of contours \\ Provides more information on the contour classification, intended to help identify additional features \\ as being depressions \\ $0=$ Depression status is indeterminate (unable to close as a polygon) \\ $1=$ Feature is a depression contour \\ $2=$ Feature is a normal contour \\ $0=$ Normal contour. Independent of depression status \\ $1=$ Index contour. Independent of depression status. Typically every 5 th contour is flagged as an \\ index. \\ An integer representing a unique USGS catalog item. Replaces MapID \\ The date the contours were generated \\ Old USGS catalog number on topographic quadrangles (for example 8097e1) \\ For future use \\ The most recent date of DEM source data in a quad \\ Feature length in decimal degrees
}

\section{Appendix 2. Abbreviations}

ArcGIS GIS software by the Environmental Research Systems Institute

CONUS conterminous United States

DEM Digital Elevation Model

GIS Geographic Information Systems

GNIS Geographic Names Information System

IDW Inverse Distance Weighted

lidar Light Detection and Ranging

NAD $29 \quad$ North American Datum of 1929

NAD $83 \quad$ North American Datum of 1983

NAVD $88 \quad$ North American Vertical Datum of 1988 


$\begin{array}{ll}\text { NED } & \text { National Elevation Dataset } \\ \text { NGVD 29 } & \text { National Geodetic Vertical Datum of } 1929 \\ \text { NHD } & \text { National Hydrography Dataset } \\ \text { NOAA } & \text { National Oceanic and Atmospheric Administration } \\ \text { TIN } & \text { Triangulated Irregular Network } \\ \text { USGS } & \text { U.S. Geological Survey }\end{array}$


Publishing support provided by:

Rolla Publishing Service Center

For more information concerning this publication, contact:

U.S. Geological Survey Earth Resources Observation and Science (EROS) Center

47914 252nd Street

Sioux Falls, South Dakota 57198

(605) 594-6151

Or visit the EROS Center Web site at:

http://eros.usgs.gov/ 



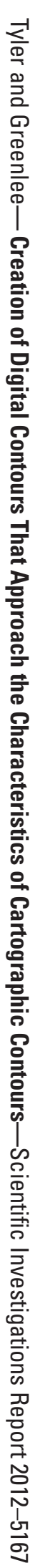

